\section{COVID19: A Matter of State and Faith}

Sir,

SARS-CoV2 (severe acute respiratory syndrome, coronavirus 2 ), the trending microorganism, has been the centre of discussion in every household. It is a single-strand positive sense RNA virus that spreads via respiratory droplets. At this point, almost everyone knows what it is, what disease it causes, and how to protect oneself. In this letter, we address the socio-religious implications of this novel virus.

Our society revolves around the concept of family and togetherness. In any other situation, these are valuable traits to have; but our people are facing, for the first time, a calamity that asks us to abandon our core principles. We must not be rash in presuming this is an easy change to make. That being said, a lax attitude will cost us heavily.

As the Pakistani society transitions into an aging population, we stand vulnerable to this novel virus, because the death rate is known to rise with advancing age, especially among those with comorbidities, such as hypertension that has a prevalence of $35.1 \%$ in Pakistan ${ }^{1}$ and carries a death rate of $6 \%$. Similarly, the case fatality in diabetes is $7.3 \%$, cardiovascular disease $10.5 \%$, chronic respiratory disease $6.3 \%$, and cancer of any type $5.6 \%{ }^{2}$

A sharp surge in misinformation has been seen across all social media platforms, suggesting inappropriate preventive measures, non-FDA approved treatments and bogus spiritual remedies. Providing citizens with authentic information from state sponsored or international agencies is needed to halt the propagation of paranoia that comes with misinformation.

The duty of the government is unquestionable in containing this pandemic, but the purpose of this letter is also to highlight the role that can be played by local leaders; especially religious scholars. Every street has a mosque and every mosque has a congregation every week, if not every day. If a uniform message is conveyed to the masses by the said religious scholars, a greater degree of compliance to self-isolation and social-distancing can be achieved.

Last but not least, it lies upon the common people to be able to recognise the gravity of the situation. It is important, they understand that asymptomatic carriers can transmit the virus to others, more vulnerable people. ${ }^{3}$ Undue anxiety may lead to anarchy and chaos, but too laidback of an approach to this pandemic leads to complacency. It falls on the leaders of our society, be it the state or religious scholars, to orchestrate this balancing act.

While it is true that we lack the infrastructure and facilities that others have, more economically stable nations may possess; but instead, we have significant online and even deeper offline networks that can be used to convey accurate and contemporary information to this ever-changing problem.

\section{CONFLICT OF INTEREST:}

Authors declared no confilct of interest.

\section{AUTHORS' CONTRIBUTION:}

AS: Conceptualisation; project administration; supervision; writing original draft; writing review and editing.

ZH: Conceptualisation; writing review and editing.

MSK: Conceptualisation; visualisation; writing review and editing.

\section{REFERENCES}

1. Shafi ST, Shafi T. A survey of hypertension prevalence, awareness, treatment, and control in health screening camps of rural central Punjab, Pakistan. J Epidemiol Global Health 2017; 7(2):135-40.

2. The novel coronavirus pneumonia emergency response epidemiology team. The epidemiological characteristics of an outbreak of 2019 novel coronavirus diseases (COVID-19) - China, 2020[J]. China CDC Weekly 2020; 2(8):113-22.

3. Bai Y, Yao L, Wei T, Tian F, Jin DY, Chen L, et al. Presumed asymptomatic carrier transmission of COVID-19. Jama 2020; 323(14):1406-7.

Abuzar Siraj', Zair Hassan ${ }^{2}$ and Muhammad Shahbaz Khan ${ }^{2}$

${ }^{1}$ Hayatabad Medical Complex, Hayatabad, Peshawar, Pakistan

${ }^{2}$ Lady Reading Hospital, Peshawar, Pakistan

Correspondence to: Dr. Abuzar Siraj, Hayatabad Medical Complex, Hayatabad, Peshawar, Pakistan

E-mail: abuzar.siraj96@gmail.com

Received: March 23, 2020; Revised: March 31, 2020;

Accepted: April 13, 2020

DOI: https://doi.org/10.29271/jcpsp.2020.JCPSPCR.CR81 